\title{
A new, lateral, continuous, combined, femoral- sciatic nerve approach via a single skin puncture for postoperative analgesia in intramedullary tibial nail insertion
}

Luiz Eduardo Imbelloni ${ }^{1,2}$

Carlos Rava ${ }^{1,3}$

Marildo A Gouveia ${ }^{2}$

'Faculdade de Medicina Nova

Esperança, ${ }^{2}$ Institute for Regional Anesthesia, ${ }^{3}$ Complexo Hospitalar de Mangabeira Governador Tarcisio Burity, João Pessoa, Brazil
Correspondence: Luiz Eduardo Imbelloni Rua Francisco Diomedes Cantalice, 21/802, Cabo Branco, 58045-210, João Pessoa, PB, Brazil

Email dr.imbelloni@terra.com.br
This article was published in the following Dove Press journal:

Local and Regional Anesthesia

14 February 2013

Number of times this article has been viewed

Background: The prevalence of anterior knee pain following intramedullary tibial nail insertion is high. Continuous peripheral nerve blockade is an alternative method of pain control to opiods. This case illustrates the use of femoral nerve and sciatic nerve peripheral catheters with an elastomeric infusion pump for major intramedullary nailing surgery.

Case report: A 36-year-old male with fractures to the left leg bones presented for placement of an intramedullary nail under spinal anesthesia. At the end of the procedure, access to the lateral femoral and sciatic continuous nerve block was achieved by using a stimulator connected to a $110 \mathrm{~mm} \mathrm{18G} \mathrm{Tuohy} \mathrm{needle.} \mathrm{Postoperative} \mathrm{analgesia} \mathrm{was} \mathrm{provided} \mathrm{with} \mathrm{a} \mathrm{40-hour} \mathrm{infusion}$ of $0.1 \%$ bupivacaine $(400 \mathrm{~mL})$ at a rate of $10 \mathrm{~mL}_{\text {hour }}{ }^{-1}$ with an elastomeric pump. Anesthetic dispersion and contrast were investigated. The analog scale remained with scores below 3 during the 40 hours after surgery, and boluses were not necessary.

Conclusion: The use of a femoral and sciatic nerve peripheral catheter offered an alternative to conventional pain control. Continuous femoral-sciatic peripheral blockade via a skin puncture with an infusion of $0.1 \%$ bupivacaine with elastomeric pumps is a safe and effective procedure in adults.

Keywords: local anesthetic, bupivacaine, continuous peripheral nerve block, orthopedic surgery, tibia, elastomeric pump

Tibial shaft fracture is one of the most common types of long-bone fractures in orthopedic practice. Reamed intramedullary nailing is now commonly used in the management of tibial shaft fractures and is considered by some to be the treatment of choice in closed displaced fractures. ${ }^{1}$ After appropriate fracture reduction, one of three skin incisions may be used: a $5 \mathrm{~cm}$ longitudinal incision made medial to the patellar tendon between the tibial tubercle and the inferior border of the patella, a $5 \mathrm{~cm}$ longitudinal incision made transpatellar to the tendon between the tibial tubercle and the inferior border of the patella, or a transverse incision midway between the joint and tibial tuberosity. Anterior knee pain is the most common complication after intramedullary nailing of the tibia. ${ }^{2}$ The prevalence of chronic anterior knee pain following intramedullary tibial nail insertion has been reported as being between $10 \%{ }^{3}$ to $86 \%{ }^{2}$ However, a recent meta-analysis of the literature estimated the incidence at $47.4 \%{ }^{4}$

Lumbar plexus block when combined with sciatic nerve block is a safe and effective alternative for analgesia in lower limb surgery. A lateral approach to sciatic-femoral block combined via a single skin injection was recently described. ${ }^{5}$ The objective 
of the present report was to describe a lateral, continuous, combined, femoral-sciatic nerve approach with a portable elastomeric device in a patient undergoing intramedullary tibial nail insertion.

\section{Case report}

A 36-year-old man (66 kg, $170 \mathrm{~cm}$, physical status American Society of Anesthesiology [ASA] I) with fractures to the left leg bones was scheduled for an intramedullary nail under spinal anesthesia. The patient was evaluated and signed the informed consent to undergo a single needle entry combined approach of continuous peripheral blocks (Figure 1). After routine monitoring, spinal anesthesia was performed with a 27G Quincke needle (BBraun, Melsungen, Germany) in the $\mathrm{L}_{3}-\mathrm{L}_{4}$ space through a median approach with the patient in a lateral position. The patient was injected with $15 \mathrm{mg}$ of isobaric $0.5 \%$ bupivacaine.

During the procedure, the patient was supine on a radiolucent table. Nail length was determined under traction with image intensification. A transpatellar approach was used for the proximal tibia, which was opened with a solid awl under image intensification. The proximal fracture site was opened and a reaming rod was inserted; the distal fracture site was reduced and closed. The segmentar fragment was locked with a Schanz screw. The canal was reamed, and one poller screw was inserted in the distal fragment. We introduced a $9 \mathrm{~mm}$ diameter cannulated nail and achieved distal locking with two screws (freehand locking technique). Proximal locking was with two screws. An end cap was inserted.

During the procedure, $1000 \mathrm{~mL}$ of crystalloids and $500 \mathrm{~mL}$ of Voluven ${ }^{\circledR}$ (6\% hydroxyethyl starch 130/0.4 in $0.9 \%$ saline) were administered. No urinary catheter was utilized during the procedure.
At the end of the procedure, access to lateral femoral and sciatic continuous nerve block was achieved using a stimulator (HNS12; BBraun) connected to a $110 \mathrm{~mm} 18 \mathrm{G}$ Tuohy needle (BBraun). The needle was advanced and the quadriceps were stimulated with a $0.5 \mathrm{~mA}$ current until a response was observed. After negative aspiration of blood, $20 \mathrm{~mL}$ of $0.2 \%$ bupivacaine was injected through an extension connector of the needle. While maintaining the needle in the same position, a $20 \mathrm{G}$ catheter was inserted $7 \mathrm{~cm}$ into the inguinal compartment and was fixed in place with adhesive material and an occlusive dressing. Another needle was then advanced posteriorly and caudally to reach the sciatic nerve, which was identified by stimulation of the common fibular nerve or tibial nerve, confirmed by movements of the foot. We then injected $20 \mathrm{~mL}$ of the same anesthetic solution. Approximately $5 \mathrm{~mL}$ of contrast (iohexol with $300 \mathrm{mg} \mathrm{mL}^{-1}$ Ominipaque $^{\circledR}$ ) was injected in each catheter to study the dispersion of the local anesthetic, and an anteroposterior X-ray was taken within 1 minute (Figure 2).

Before his discharge, a disposable elastomeric pump (Easypump $^{\circledR}$, BBraun) containing $400 \mathrm{~mL}$ of $0.1 \%$ bupivacaine was connected to the catheters of both nerves. The pump was programmed for infusion at a rate of $10 \mathrm{~mL} \cdot$ hour $^{-1}$. Upon completion the patient was transferred to the postanesthesia care unit. An analog scale was used to divide patients pain into categories of mild or no pain (0-3), moderate pain (4-7), and severe pain (8-10). The patient remained with scores below 3 during the 40 hours after surgery. He received instructions to trigger the bolus device, which is part of the pump, in case of severe pain. Toxicity symptoms of the local anesthetic were recorded. During the 40 postoperative hours, boluses were not necessary. Both catheters were removed without

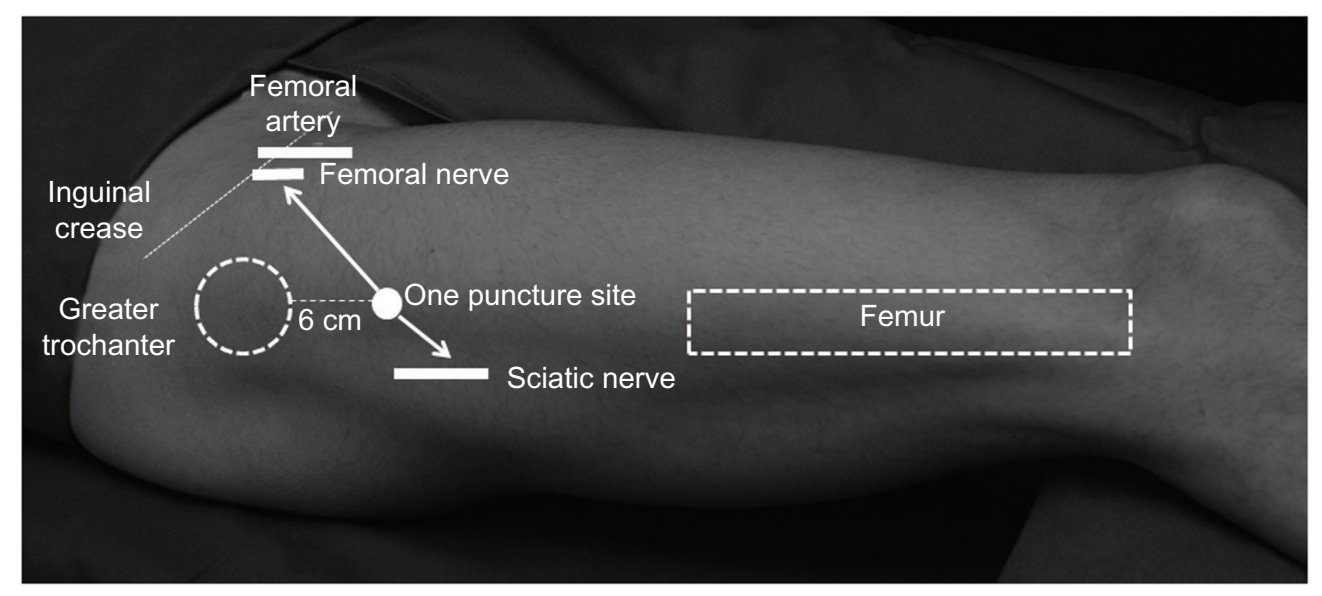

Figure I Diagram for insertion of the needle. 


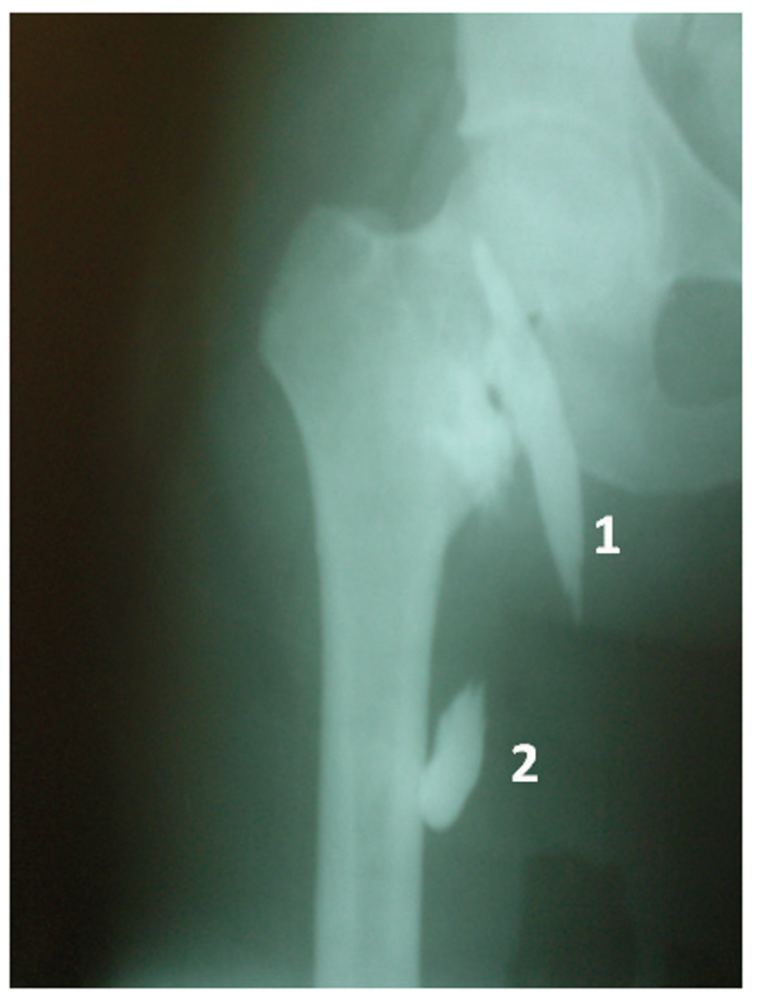

Figure $\mathbf{2}$ The spread of contrast in combined continuous femoral and sciatic nerve block.

Notes: $\mathbf{I}$ is the spread of contrast in the continuous femoral nerve block; $\mathbf{2}$ is the spread of contrast in the continuous sciatic nerve block.

intercurrences and were sent for bacteriological examination after removal; pain was then controlled with oral ketoprofen and dypirone.

\section{Discussion}

The use of a lateral, continuous, combined, femoral-sciatic nerve approach via a single skin puncture for postoperative analgesia for tibial intramedullary nailing has not been reported. Since this method administers a local anesthetic close to the continuous combined femoral-sciatic nerve, analgesia can be prolonged, especially in patients with a tibial shaft fracture. The results of this case demonstrate that an elastomeric pump for a continuous peripheral nerve block with infusion of a local anesthesia in adult patients is an effective and safe analgesic method after extensive orthopedic procedures. The use of rescue analgesia was minimal.

Although many closed fractures of the tibial shaft can be treated nonoperatively, ${ }^{6}$ there are numerous indications for operative treatment. The choice of surgical approach, specifically using the transpatellar or parapatellar tendon, has been reported as a contributory factor in chronic anterior knee pain following tibial nail insertion. In a retrospective study in which a nail was inserted via a paratendinous incision in 65 fractures and via a tendon-splitting incision in 36 fractures, insertion of an intramedullary nail through the paratendinous incision resulted in a $50 \%$ incidence of knee pain, whereas this incidence in the transtendinous incision group was $77 \% .^{7}$ This is in contrast to other reports of no significant difference. ${ }^{8}$ In this case study the incision was transpatellar.

A lateral entrance in the inguinal lumbar plexus allows the needle to find the femoral nerve before reaching the femoral artery. An entry perpendicular and below the greater trochanter reaches the sciatic nerve after touching the femur bone. The lateral entrance reduced the risk of lateral displacement, facilitating the movement of the patient and allowing personal hygiene, such as changing the dressing to reduce the risk of infection.

The use of bupivacaine $(0.1 \%$ to $0.25 \%)$ as used in our case study did not result in toxic blood levels in postoperative analgesia for 24-72 hours. ${ }^{9}$ The venous level of bupivacaine during continuous lumbar plexus

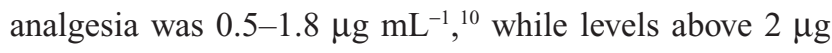
$\mathrm{mL}^{-1}$ are considered toxic. Continuous peripheral nerve block analgesia, regardless of catheter location, provided superior postoperative analgesia and fewer opioid-related side effects when compared with an opioid analgesia. ${ }^{11}$ In surgery, the continuous plexus block is used primarily to improve the quality of postoperative analgesia and allow early rehabilitation. There was no difference in pain between rest and movement, showing that continuous analgesia decreased the incidence of postoperative pain to 3 on the visual analog scale during the 48 hours following the operation.

A lateral, continuous, combined, femoral-sciatic block was performed with a peripheral nerve stimulator, and we observed the distribution of contrast around both nerves. The distribution of contrast showed a higher level in the inguinal region through the femoral nerve and below the subtrochanteric femur in the region through the sciatic nerve.

Portable pumps are increasingly being used in continuous regional anesthesia. Those pumps are frequently used in outpatients without medical supervision. If the elastomeric pump lies below the catheter tip, the delivery of the agent can be impaired to a variable extent. Our case study demonstrated that the patient received adequate analgesia in both catheters. The rate of flow of the anesthetics is dictated by the elastomeric reservoir and the gauge of the tube, which prevents the infusion of a large bolus and overdose. Although the pump has its own bacterial filter, we used a second filter to increase patient safety. The elastomeric pump has several advantages over the 
electronic pump, including portability, ease of use, and few technical problems, such as undesirable alarms. ${ }^{12}$

Severe infectious complications have been reported after continuous blockade, with about $29 \%$ of peripheral nerve catheters being colonized with up to $3 \%$ bacteria, resulting in localized inflammation. ${ }^{13}$ Continuous peripheral nerve block (CPNB) duration ( $>48$ hours) was a strong risk factor for local infectious problems. ${ }^{13}$ We prospectively reported an incidence of $57 \%$ colonized femoral catheters $(1.5 \%$ with bacteremia) after 48 hours of continuous infusion of bupivacaine or ropivacaine. ${ }^{14}$ Given the results of infection after 48 hours, the pump was scheduled to stop 48 hours after surgery. With lateral access to the axilar brachial plexus and inguinal lumbar plexus, we did not observe any bacterial growth in 20 catheters, similar to our finding that in 48 hours there was no sign of inflammation at the puncture site. ${ }^{15}$ Likewise, bacteriological examination of both catheters found no bacterial growth.

\section{Conclusion}

The use of extended local anaesthesia for postoperative pain has previously been reported and has several advantages over other methods, including ease of placement, safety, reliability, lower cost, and effectiveness. We conclude that continuous femoral-sciatic peripheral nerve block via a single skin puncture with infusion of $0.1 \%$ bupivacaine via an elastomeric pump is a safe and effective procedure in adults for surgical treatment of tibia fractures by intramedullary nailing.

\section{Disclosure}

The authors have no conflicts of interest to report.

\section{References}

1. Court-Brown CM, Will E, Christie J, McQueen MM. Reamed or unreamed nailing for closed tibial fractures. A prospective study in Tscherne C1 fractures. J Bone Joint Surg. 1992;74-B:770-774.
2. Toivanen JA, Vaisto O, Kannus P, Latvala K, Honkonen SE, Jarvinen MJ. Anterior knee pain after intramedullary nailing of fractures of the tibial shaft. A prospective, randomized study comparing two different nailinsertion techniques. J Bone Joint Surg Am. 2002;84-A:580-585.

3. Karachalios T, Babis G, Tsarouchas H, et al. The clinical performance of a smaller diameter tibial nailing system with a mechanical distal aiming device. Injury. 2003;31:451-459.

4. Katsoulis E, Court-Brown C, Giannoudis PV. Incidence and aetiology of anterior knee pain after intramedullary nailing of the femur and tibia. J Bone Joint Surg Br. 2006;88-B:576-580.

5. Imbelloni LE. A new lateral combined femoral-sciatic nerve approach via a single skin puncture (Letter to Editor). J Pain Relief. 2012;1:102.

6. Nicoll EA. Fractures of the tibial shaft. A survey of 705 cases. Bone and Joint Surg. 1964:46-B:373-387.

7. Keating JF, Orfaly R, O’Brien PJ. Knee pain after tibial nailing. J Orthop Trauma. 1997;11:10-13.

8. Väistö $\mathrm{O}$, Toivanen J, Paakkala T, Järvelä T, Kannus P, Järvinen M. Anterior knee pain after intramedullary nailing of a tibial shaft fracture. An ultrasound study of the patellar tendons of 36 patients. J Orthop Trauma. 2005;19:311-316.

9. Liu SS, Salinas FV - Continuous plexus and peripheral nerve blocks for postoperative analgesia. Anesth Analg. 2003;96:263-272.

10. Anker-Moller E, Spangsbersg N, Dahl JB, et al. Continuous blockade of the lumbar plexus after knee surgery: a comparison of the plasma concentrations and analgesic effect of bupivacaine $0.250 \%$ and $0.125 \%$. Acta Anaesthesiol Scand. 1990;34:468-472.

11. Richman J, Liu SS, Courpas G, et al. Does continuous peripheral nerve block provide superior pain control to opioids? A meta-analysis. Anesth Analg. 2006;102:248-257.

12. Capdevila X, Macaire P, Aknin P, et al. Patient-controlled perineural analgesia after ambulatory orthopedic surgery: a comparison of electronic versus elastomeric pumps. Anesth Analg. 2003;96:414-417.

13. Capdevila X, Pirat P, Bringuier S, et al; French Study Group on Continuous Peripheral Nerve Blocks. Continuous peripheral nerve blocks in hospital wards after orthopedic surgery. A multicenter prospective analysis of the quality of postoperative analgesia and complications in 1416 patients. Anesthesiology. 2005;103:1035-1045.

14. Cuvillon P, Ripart J, Lalourcey L, et al. The continuous femoral nerve block catheter for postoperative analgesia: bacterial colonization, infectious rate and adverse effects. Anesth Analg. 2001;93:1045-1049.

15. Imbelloni LE, Silva Neto EJ, Carneiro AF, Lobão A, Imperiano B, Grigório R. A new continuous lateral access to axillary and femoral nerves decreases pain in movement and catheter contamination. Sci $J$ Med Clin Trials. 2012;2:1-8.
Local and Regional Anesthesia

\section{Publish your work in this journal}

Local and Regional Anesthesia is an international, peer-reviewed, open access journal publishing on the development, pharmacology, delivery and targeting and clinical use of local and regional anesthetics and analgesics. The journal welcomes submitted papers covering original research, basic science, clinical studies, reviews \& evaluations,

\section{Dovepress}

guidelines, expert opinion and commentary, case reports and extended reports. The manuscript management system is completely online and includes a very quick and fair peer-review system, which is all easy to use. Visit http://www.dovepress.com/testimonials.php to read real quotes from published authors. 